\title{
EVALUASI PENGGUNAAN EDMODO TERHADAP MOTIVASI DAN KOMPETENSI BAGI MAHASISWA
}

\author{
Alhibarsyah \\ Sistem Informasi \\ STMIK Tunas Bangsa \\ Jl. ZA. Pagar Alam No. 17A Rajabasa, Bandar Lampung \\ Alhibarsyah.aal@gmail.com
}

\begin{abstract}
ABSTRAK
Keterlibatan e-learning dalam dunia pendidikan sekarang ini, bukan lagi dianggap sebagai hal yang baru, akan tetapi sudah menjelma menjadi salah satu kebutuhan yang harus dimiliki dan dimanfaatkan semaksimal mungkin oleh perguruan tinggi. Hal ini harus dilakukan apabila perguruan tinggi tersebut ingin meningkatkan kualitas perguruan tinggi kepada para stakeholder, dan meningkatkan keunggulan bersaing (competitive advanced) dengan perguruan tinggi lainnya. Sudah menjadi kenyataan bahwa perguruan tinggi yang memiliki reputasi, menerapkan e-learning dalam berbagai kegiatan dalam proses perkuliahan, baik dalam pemberian materi kuliah, tugas-tugas dan diskusi, agar peran e-learning dapat berjalan dengan maksimal maka perlu adanya perencanaan yang baik, implementasi yang sesuai dengan rencana yang sudah disusun, dan evaluasi yang dilakukan secara terus-menerus, atau harus selaras dan mendukung visi, misi, dan tujuan perguruan tinggi, sehingga dapat meningkatkan motivasi dan kompetensi perkuliahan bagi mahasiswa. Dengan adanya e-learning edmodo di harapkan dapat meningkatkan kompetensi pada mahasiswa dari segi kombinasi dari keterampilan (skill), pengetahuan (knowledge), dan perilaku yang dapat diamati dan diterapkan secara kritis untuk suksesnya sebuah sistem pembelajaran dengan alat bantu internet serta kontribusi pribadi terhadap sistem pembelajaran tersebut serta meningkatkan motivasi yang mendorong atau menjadi sebab seseorang melakukan suatu kegiatan atau perbuatan yang berlangsung secara sadar. Salah satu pendukung e-learning yang digunakan saat ini yaitu edmodo karena edmodo merupakan suatu jejaring sosial berbentuk pembelajaran yang banyak membantu dosen dan mahasiswa dalam proses perkuliahan dan perkuliahan tanpa batasan menggunakan teknologi maklumat. Laman web Edmodo berfungsi sama seperti laman sosial yang lain seperti "Facebook" dan "Twitter" tetapi Edmodo lebih menekankan aspek pembelajaran secara maya. Edmodo dirancang untuk membuat mahasiswa bersemangat belajar di lingkungan yang lebih akrab. Dalam Edmodo, dosen dapat melanjutkan diskusi kelas online, memberikan penilaian serta pemahaman mahasiswa dan lencana penghargaan kepada mahasiswa secara individual berdasarkan kinerja atau perilaku.
\end{abstract}

Salah satu alat yang digunakan untuk mengevaluasi tingkat motivasi dan kompetensi penggunaan elearning edmodo adalah COBIT (Control Objectives for Information and Related Technology) yang di tekan pada domian Deliver and Support (DS) domain ini menitikberatkan pada teknis-teknis yang mendukung terhadap proses penggunaan edmodo dan Monitor and Evaluate (ME) Domain ini dikonsentrasikan pada monitoring dan evaluasi penggunaan edmodo. COBIT suatu model standar yang menyediakan dokumentasi best practice pengelolaan e-learning yang dapat membantu pihak akademik khususnya dosen dan mahasiswa untuk menjembatani proses perkuliahan.

Dalam penelitian ini akan dibagikan kuesioner kepada dosen dan mahasiswa. Data ini akan diolah untuk melihat tingkat kematangan atau maturity level dari masing-masing control objective yang ada pada domain Deliver and Support serta domain Monitor and Evaluate. Apabila terjadi gap antara current maturity dan expected maturity, maka akan dibuat rekomendasi prosedur apa saja yang harus diikuti untuk menutup gap tersebut, sehingga expected maturity dapat tercapai. Hasil pengujian terhadap hipotesis menunjukkan bahwa hasil akhir dari perhitungan maturity level yang dihitung tingkat motivasi dan kompetensi (maturity level) dalam penelitian ini, adalah semua proses-proses penggunaan edmodo dalam 2 (dua) domain COBIT, yaitu Deliver and Support (DS) dan Monitor and Evaluate (ME). sehingga hasil akhir yang diperoleh pada penelitian ini 
adalah bahwa e-learning edmodo sangat berpengaruh terhadap motivasi dan komptensi perkuliahan bagi mahasiswa. Variabel motivasi yang dipengaruhi variabel kompetensi berpengaruh terhadap edmodo. Pengaruh variabel edmodo berinteraksi dengan variabel motivasi berpengaruh terhadap variabel kompetensi.

Kata kunci : Motivasi, Kompetendi, e-Learnig, edmodo, COBIT

\begin{abstract}
s
The involvement of e-learning in the world of education today is no longer regarded as a new thing, but has become one of the needs that must be owned and utilized as much as possible by universities. This must be done if the tertiary institution wants to improve the quality of higher education institutions to stakeholders, and increase competitive advanced with other universities. It has become a reality that universities that have a reputation, implement e-learning in various activities in the lecture process, both in giving lecture material, assignments and discussions, so that the role of e-learning can run optimally, there needs to be good planning, implementation in accordance with the plans that have been prepared, and evaluations carried out continuously, or must be aligned and support the vision, mission, and objectives of the college, so as to increase the motivation and competence of lectures for students. With the e-learning edmodo is expected to be able to improve the competence of students in terms of a combination of skills, knowledge, and behavior that can be observed and applied critically to the success of a learning system with internet tools and personal contributions to the system learning and increasing motivation that drives or becomes because someone does an activity or action that takes place consciously. One of the supporters of e-learning that is used today is Edmodo because Edmodo is a social network in the form of learning that helps lecturers and students in the lecture process and lectures without limitation using information technology. Edmodo's web site functions the same as other social pages such as "Facebook" and "Twitter" but Edmodo emphasizes the aspect of learning in a virtual way. Edmodo is designed to make students eager to learn in a more familiar environment. In Edmodo, lecturers can continue online class discussions, provide student assessment and understanding and award badges to students individually based on performance or behavior.
\end{abstract}

One of the tools used to evaluate the level of motivation and competence in the use of edmodo elearning is COBIT (Control Objectives for Information and Related Technology) which is pressed into the Deliver and Support (DS) domain. This domain focuses on technical support for the usage process edmodo and Monitor and Evaluate (ME) This domain is concentrated on monitoring and evaluating the use of edmodo. COBIT is a standard model that provides best-practice e-learning management documentation that can help academics, especially lecturers and students, to bridge the lecture process.

In this study questionnaires will be distributed to lecturers and students. This data will be processed to see the maturity level of each control objective in the Deliver and Support domain and the Monitor and Evaluate domain. If there is a gap between current maturity and expected maturity, any procedure recommendations will be made that must be followed to close the gap, so that the expected maturity can be achieved. The test results on the hypothesis indicate that the final result of the calculation of the maturity level calculated by the level of motivation and competency (maturity level) in this study, is all the processes of using edmodo in 2 (two) COBIT domains, namely Deliver and Support (DS) and Monitor and Evaluate (ME). so the final results obtained in this study are that edmodo e-learning has a profound effect on the motivation and competence of lectures for students. Motivational variables that are influenced by competency variables affect Edmodo. The effect of the Edmodo variable interacts with the motivation variable influencing the competency variable.

Keywords: Motivation, Competency, e-Learnig, edmodo, COBIT

\section{PENDAHULUAN}

Penggunaan teknologi informasi pada suatu perguruan tinggi tentunya akan membanwa banyak keuntungan bagi perguruan tinggi itu sendiri. Peningkatan peran teknologi informasi nantinya harus berbanding lurus dengan kualitas perguruan itu sendiri. Hal ini akan membutuhkan perencanaan yang matang dalam pelaksanaannya nanti. Untuk itulah diperlukan adanya e-learning yang baik pada perguruan itu di mulai dari 
prencanaan sampai dengan implementasi, agar proses pembalajaran dapat berjalan secara optimal.

Sistem pembelajaran dengan menggunakan internet dinegara kita bukanlah hal yang baru, namun pemanfaatannya belumlah maksimal dan masih perlu sosialisasi tentang internet baik kepada masyarakat umum terutama para mahasiswa. Dengan berbagai pendekatan yang benar dalam penerapannya diperlukan sosialisasi yang seimbang dengan peralihan pemikiran yang lebih positif. Dan yang lebih penting peran para Dosen harus bersikap positif dan memperkenalkan kepada mahasiswa terhadap konsep pembelajaran dengan menggunakan internet dan juga media pembelajaran online atau e-learning dan lain-lain.

E-learning yang digunakan di STMIK DCC menggunakan aplikasi edmodo yang merupakan suatu jejaring sosial berbentuk pembelajaran yang banyak membantu dosen dan mahasiswa dalam proses perkuliahan dan perkuliahan tanpa batasan menggunakan teknologi maklumat. Laman web Edmodo berfungsi sama seperti laman sosial yang lain seperti "Facebook" dan "Twitter" tetapi Edmodo lebih menekankan aspek pembelajaran secara maya.

Edmodo dirancang untuk membuat mahasiswa bersemangat belajar di lingkungan yang lebih akrab. Dalam Edmodo, dosen dapat melanjutkan diskusi kelas online, memberikan penilaian serta pemahaman mahasiswa dan lencana penghargaan kepada mahasiswa secara individual berdasarkan kinerja atau perilaku.

Edmodo memudahkan melacak kemajuan mahasiswa. Semua nilai dan rencana kuliah ditugaskan atau diberikan melalui Edmodo disimpan dan mudah diakses. oleh dosen bisa mendapatkan masukan dari ruang kelas melalui reaksi mahasiswa untuk kuis, tugas dan posting diskusi yang menangkap pemahaman, kebingungan, atau kefrustrasian mahasiswa.

Permukaan Edmodo yang menarik, mudah menggunakan aplikasi yang personalisasi pembelajaran untuk setiap mahasiswa. Aplikasi ini membantu dosen untuk memperkuat rencana perkuliahan mereka dengan mengintegrasikan dengan Edmodo, yang memberikan semua konten digital dalam satu tempat.
Edmodo menggunakan desain yang mirip dengan Facebook dan menyediakan ruang untu dosen dan mahasiswa tempat yang aman untuk menghubungkan, berkolaborasi dan berbagi konten. dosen juga dapat mengirim nilai, tugas dan kuis untuk mahasiswa.

Mahasiswa dapat mengajukan pekerjaan rumah dan melihat nilai - nilai mereka dan komentar dosen mungkin telah diposting tentang tugas mereka. Dosen juga dapat membuat jajak pendapat dan topik posting untuk diskusi di kalangan siswa/mahasiswa.

Dosen dapat membedakan dan menciptakan belajar mandiri melalui penciptaan subkelompok dalam kuliah. Setelah setiap periode kuliah selesai, dosen menutup keluar jaringan dan menciptakan yang baru untuk kelas berikutnya.

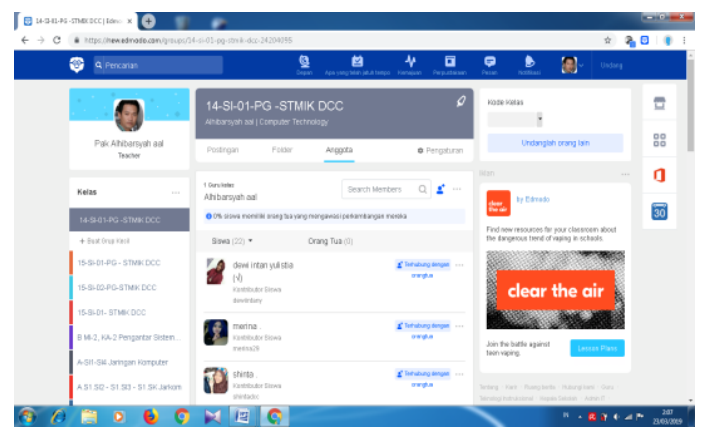

Gambar 1. Tampilan Edmodo STMIK DCC Kotabumi

Dalam upaya mencegah orang luar bergabung dengan jaringan kampus, Edmodo menyediakan kode khusus untuk kampus dan kelas. Kode ini diberikan kepada mahasiswa dan diperlukan untuk bergabung dengan kelompok.

E-Learning adalah pembelajaran yang menggunakan TIK untuk mentransformasikan proses pembelajaran antara pendidik dan peserta didik. Tujuan utama penggunaan teknologi ini adalah meningkatkan efisiensi dan efektivitas, transparansi, dan akuntabilitas pembelajaran. Di samping itu, suatu E- Learning juga harus mempunyai kemudahan bantuan profesional isi pelajaran secara on line. Dari uraian tersebut jelas bahwa E-Learning menggunakan teknologi informasi dan komunikasi sebagai alat; dengan tujuan meningkatkan efisiensi, efektivitas, transparansi, akuntabilitas, dan kenyamanan belajar; dengan obyeknya adalah layanan pembelajaran yang lebih baik, menarik, 
interaktif, dan atraktif. Hasil akhir yang diharapkan adalah peningkatan prestasi dan kecakapan akademik peserta didik serta pengurangan biaya, waktu, dan tenaga untuk proses pembelajaran (Budi Murtiyasa, 2012).

Motivasi adalah suatu kondisi yang mendorong atau menjadi sebab seseorang melakukan suatu kegiatan atau perbuatan yang berlangsung secara sadar. Secara sederhana motivasi dapat dibedakan dalam dua bentuk yaitu intrinsik dan ekstrinsik. Motivasi intrinsic adalah pendorong yang bersumber dalam diri seseorang sebagai individu, berupa kesadaran mengenai pentingnya manfaat atau makna dari hal yang dilakukan. Sedangkan motivasi ekstrinsik adalah pendorong yang bersumber dari luar seseorang sebagai individu, berupa kondisi yang mengharuskannya melaksanakan sesuatu secara maksimal. (L.R Gay, Educational Research, 1997).

Menurut Watson-Watt yang dikutip oleh Ruky (2003:106) "Kompetensi adalah kombinasi dari keterampilan (skill), pengetahuan (knowledge), dan perilaku yang dapat diamati dan diterapkan secara kritis untuk suksesnya sebuah sistem pembelajaran dengan alat bantu internet serta kontribusi pribadi terhadap sistem pembelajaran tersebut".

Berdasarkan latar belakang maka dilakukan suatu analisis pengaruh motivasi dan kompetensi, pengaruh penggunaan edmodo bagi mahasiswa. Dengan tujuan memberikan masukan dan bahan pertimbangan bagi para dosen dan pimpinan dalam penyelenggaraan perkuliahan yang menggunakan internet sebagai alat bantu proses perkuliahan. dan bagi mahasiswa diharapkan hasil penelitian ini dapat memberikan wacana positif terhadap sistem perkuliahan yang menggunakan edmodo, sehingga para mahasiswa termotivasi untuk menggali kompetensi diri serta dapat mengembangkan materi kuliah dengan menggunakan media perkuliahan secara online atau e-learning.

\section{METODE PENELITIAN}

Ekspektasi motivasi, dan ekspektasi kompetensi dengan kondisi-kondisi yang memfasilitasi pemakai merupakan variabel independen diukur berdasarkan instrumen Davis et al., (1989); Moore dan Benbasat, (1991); Thompson et al., (1991). Instrumen tersebut dinilai dengan menggunakan skala interval 5 poin. Dalam penelitian ini, pengaruh Edmodo sebagai variable moderasi dan sikap pembelajaran mahasiswa sebagai variabel dependen diukur dengan menggunakan instrumen Davis et al., (1989) dan Thompson et al., (1991).

Dengan mengacu pada metode penarikan sampel tersebut di atas, maka obyek yang menjadi populasi dalam penelitian ini adalah pengelola edmodo yaitu dosen dan mahasiswa dalam hal ini yaitu mahasiswa. Jumlah dan syarat polulasi yang akan dilibatkan sebagai sampel.

1. Pengelola Edmodo

a. Unit TI

Syarat untuk dipilih sebagai sampel adalah minimal telah menggunakan edmodo dalam bagian tersebut.

b. Administrasi Akademik Syarat untuk dipilih sebagai sampel adalah minimal telah menggunakan edmodo dalam bagian tersebut

2. Pengguna Langsung

a. Bagian Internal (Program Studi dan Dosen Penasihat Akademik/PA). Syarat minimal telah bekerja dalam bagian tersebut dan menjadi Dosen PA.

b. Mahasiswa Jumlah populasi mahasiswa aktif, syarat untuk dipilih sebagai sampel minimal semester 3 .

Instrumen yang digunakan untuk mengukur semua variabel yang akan diteliti. Untuk mengetahui kisi-kisi pada kuesioner pada penelitian ini yang berisi variabel-variabel indikator yang digunakan untuk mengukur variabel independen, dependen dan moderasi, dapat dilihat pada Tabel 2.1.

Tabel 1. Kisi-Kisi Instrumen Penelitian

\begin{tabular}{|c|c|c|}
\hline $\begin{array}{c}\text { Variabel } \\
\text { penelitian }\end{array}$ & Dimensi & $\begin{array}{l}\text { Indikator- } \\
\text { indikator }\end{array}$ \\
\hline \multirow[t]{2}{*}{$\begin{array}{l}\text { Motivasi } \\
\text { (MO) } \\
\text { [HADARI } \\
\text { 97] }\end{array}$} & 1. Intrinsik & $\begin{array}{l}\text { M1. Kesadaran } \\
\text { untuk } \\
\text { mengakses } \\
\text { Edmodo } \\
\text { M2. Kebutuhan } \\
\text { internet untuk } \\
\text { mendukung } \\
\text { pembelajaran }\end{array}$ \\
\hline & 2. Ekstrinsik & $\begin{array}{l}\text { M3. Pengaruh } \\
\text { lingkungan } \\
\text { M4. Tuntutan } \\
\text { sistem }\end{array}$ \\
\hline $\begin{array}{l}\text { Kompe } \\
\text { tensi } \\
(\mathrm{KOM})\end{array}$ & $\begin{array}{l}\text { 1. Motif } \\
\text { (Motive) }\end{array}$ & $\begin{array}{l}\text { DS1. } \\
\text { Ketersediaan } \\
\text { materi kuliah }\end{array}$ \\
\hline
\end{tabular}




\begin{tabular}{|c|c|c|}
\hline \multirow[t]{5}{*}{$\begin{array}{l}\text { [SPENCER } \\
93]\end{array}$} & & $\begin{array}{l}\text { untuk } \\
\text { menyelesaikan } \\
\text { tugas-tugas } \\
\text { kuliah } \\
\text { DS2. Kebiasaan } \\
\text { menghasilkan } \\
\text { inovasi }\end{array}$ \\
\hline & $\begin{array}{l}\text { 2. Sifat } \\
\text { (trait) }\end{array}$ & $\begin{array}{l}\text { DS3. } \\
\text { Kesenangan } \\
\text { terhadap cara } \\
\text { belajar yang } \\
\text { kreatif }\end{array}$ \\
\hline & $\begin{array}{l}\text { 3. Konsep } \\
\text { diri (selft } \\
\text { concept) }\end{array}$ & $\begin{array}{l}\text { DS4. Keyakinan } \\
\text { untuk } \\
\text { mengerjakan } \\
\text { tugas-tugas } \\
\text { kuliah secara } \\
\text { efektif }\end{array}$ \\
\hline & $\begin{array}{l}\text { 4. Pengetah } \\
\text { uan } \\
\text { (knowled } \\
\text { ge) }\end{array}$ & $\begin{array}{l}\text { DS5. Pengertian } \\
\text { tentang internet }\end{array}$ \\
\hline & $\begin{array}{l}\text { 5. Keteramp } \\
\text { ilan }(\text { skill })\end{array}$ & $\begin{array}{l}\text { DS6. } \\
\text { Kemampuan } \\
\text { mengakses yang } \\
\text { efisien }\end{array}$ \\
\hline
\end{tabular}

Teknis analisis data yang digunakan pada penelitian ini adalah analisis deskriptif dan analisis kuantitatif.

1. Analisis Deskriptif digunakan untuk mengetahui penggunaan e-learning edmodo saat ini. Perbaikan ini akan mengacu pada detail control objective COBIT 4.0. (IT Governance Institute. 2007)

2. Analisis Kuantitatif digunakan untuk mengethaui bagaimana tingkat motivasi dan komptenesi (maturity level) mahasiswa terhadap edmodo saat ini. Hasil kuesioner yang dikumpulkan akan diolah dengan menggunakan spreadsheet Microsoft Excel.

Kuesioner COBIT maturity level yang dibagikan kepada responden digunakan untuk menghitung tingkat motivasi dan komptensi perkuliahan melalui edmodo saat ini. Kuesioner ini dibuat berdasarkan kriteria tingkat kematangan yang ditetapkan pada kerangka kerja COBIT 4.0 untuk domain DS dan ME. Skala yang digunakan dalam kuesioner ini menggunakan skala Guttman, dimana dalam kuesioner disediakan 2 (dua) pilihan jawaban $\mathrm{Y}$ (Ya) dan $\mathrm{T}$ (Tidak). Dalam perhitungannya, jawaban $\mathrm{Y}$ (Ya) dikonversi menjadi nilai 1 , dan jawaban $T$ (Tidak) dikonversi menjadi nilai 0 .

Perangkat lunak yang digunakan dalam perhitungan maturity level ini adalah Microsoft
Excel. Setelah semua hasil kuesioner dimasukkan dalam tabel, kemudian dihitung maturity level tiap proses dalam domain Deliver and Support (6 proses) dan Monitor and Evaluate (4 proses), untuk setiap responden. Hasil maturity level tiap proses dari 7 responden kemudian dicari rata-ratanya, dan hasil rata-rata tersebut akan menjadi nilai maturity level atau tingkat motivasi dan kompetensi tiap proses elearnig..

\section{HASIL DAN PEMBAHASAN}

\subsection{Perhitungan Maturity Level}

Proses-proses penggunaan edmodo yang dihitung tingkat motivasi dan kompetensi (maturity level) dalam penelitian ini, adalah semua proses-proses penggunaan edmodo dalam 2 (dua) domain COBIT, yaitu Deliver and Support (DS) dan Monitor and Evaluate (ME). Dalam domain DS dan ME proses-proses penggunaan edmodo tersebut adalah sebagai berikut.

\subsubsection{Domain Monitor and Evaluate (ME)}

Domain ini dikonsentrasikan pada monitoring dan evaluasi penggunaan edmodo, meliputi:

ME1 - Monitor and evaluate IT performance

ME2 - Monitor and evaluate internal control

ME3 - Ensure regulatory compliance

ME4 - Provide IT Governance

\subsubsection{Domain Deliver and Support (DS)}

Domain ini menitikberatkan pada teknis-teknis yang mendukung terhadap proses penggunaan edmodo, meliputi:
DS1 - Define and manage service levels
DS2 - Manage third-party services
DS3 - Manage performance and capacity
DS4 - Ensure continuous service
DS5 - Ensure systems security
DS6 - Identify and allocate costs

Hasil perhitungan tingkat penggunaan (maturity level) edmodo untuk motivasi dan kompetensi selengkapnya dapat dilihat pada tabel 2 dan tabel 3 berikut akan disampaikan hasil rekapitulasi tingkat penggunaan (maturity level) untuk domain DS dan ME.

Tabel 2. Tabel Tingkat Motivasi (maturity level) domain Deliver and Support

\begin{tabular}{|c|c|c|c|}
\hline Domain & Proses & $\begin{array}{c}\text { Current } \\
\text { Maturity }\end{array}$ & $\begin{array}{c}\text { Expected } \\
\text { Maturity }\end{array}$ \\
\hline ME1 & Monitor and & 1.300 & 3 \\
\hline
\end{tabular}




\begin{tabular}{|c|l|c|c|} 
& $\begin{array}{l}\text { evaluate IT } \\
\text { performance }\end{array}$ & \\
\hline ME2 & $\begin{array}{l}\text { Monitor and } \\
\text { evaluate } \\
\text { internal control }\end{array}$ & 1.265 & 3 \\
\hline ME3 & $\begin{array}{l}\text { Ensure } \\
\text { regulatory } \\
\text { compliance }\end{array}$ & 1.222 & 3 \\
\hline ME4 & $\begin{array}{l}\text { Provide IT } \\
\text { Governance }\end{array}$ & 1.312 & 3 \\
\hline
\end{tabular}

Tabel 3. Tabel Tingkat Kompetensi (maturity level) domain Monitor and Evaluate

\begin{tabular}{|c|c|c|c|}
\hline Domain & Proses & $\begin{array}{c}\text { Current } \\
\text { Maturity }\end{array}$ & $\begin{array}{l}\text { Expected } \\
\text { Maturity }\end{array}$ \\
\hline DS1 & $\begin{array}{l}\text { Define and } \\
\text { manage } \\
\text { service } \\
\text { levels }\end{array}$ & 2.300 & 3 \\
\hline DS2 & $\begin{array}{l}\text { Manage } \\
\text { third-party } \\
\text { Services }\end{array}$ & 2.025 & 3 \\
\hline DS3 & $\begin{array}{l}\text { Manage } \\
\text { performance } \\
\text { and } \\
\text { capacity }\end{array}$ & 2.500 & 3 \\
\hline DS4 & $\begin{array}{l}\text { Ensure } \\
\text { continuous } \\
\text { service }\end{array}$ & 1.500 & 3 \\
\hline DS5 & $\begin{array}{l}\text { Ensure } \\
\text { systems } \\
\text { security }\end{array}$ & 1,62 & 3 \\
\hline DS6 & $\begin{array}{l}\text { Identify and } \\
\text { allocate cost }\end{array}$ & 1.885 & 3 \\
\hline
\end{tabular}

Dari tabel 2-2 dan tabel 2-3 tingkat Motivasi dan Kompetensi (maturity level) domain Deliver and Support dan Monitor and Evaluate, akan dibuat representasinya dalam grafik radar, seperti yang terlihat pada gambar 2-1 dan gambar 2-2 sebagai berikut.

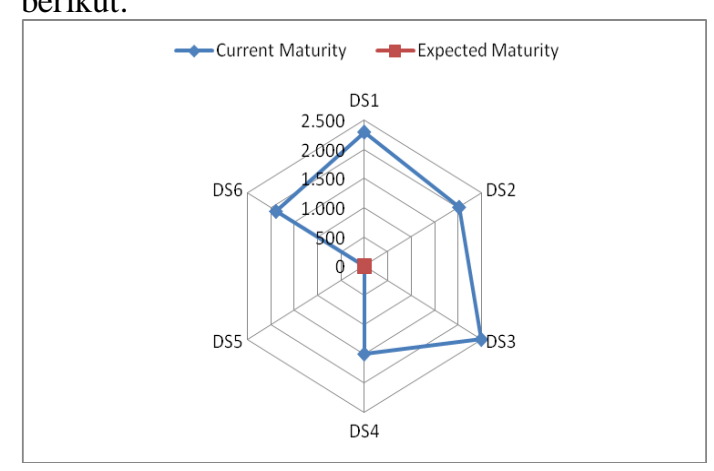

Gambar 2-1: Current maturity level vs Expected maturity level pada domain Deliver and Support

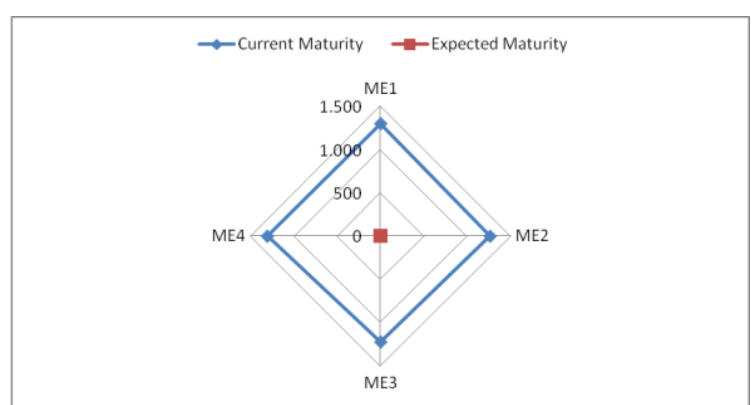

Gambar 2.2. Current maturity level vs Expected maturity level pada domain Monitor and Evaluate

Tabel 2.4 Tabel Gap tingkat kematangan (maturity level) domain Deliver and Support dan domain Monitor and Evaluate

\begin{tabular}{|c|c|c|c|}
\hline $\begin{array}{c}\text { Domai } \\
\mathbf{n}\end{array}$ & Proses & $\begin{array}{c}\text { Current } \\
\text { Maturit } \\
y\end{array}$ & $\begin{array}{c}\text { Expecte } \\
d \\
\text { Maturit } \\
y\end{array}$ \\
\hline ME1 & $\begin{array}{l}\text { Monitor and } \\
\text { evaluate IT } \\
\text { performance }\end{array}$ & 1.300 & 3 \\
\hline ME2 & $\begin{array}{l}\text { Monitor and } \\
\text { evaluate } \\
\text { internal } \\
\text { control }\end{array}$ & 1.265 & 3 \\
\hline ME3 & $\begin{array}{l}\text { Ensure } \\
\text { regulatory } \\
\text { compliance }\end{array}$ & 1.222 & 3 \\
\hline ME4 & $\begin{array}{l}\text { Provide IT } \\
\text { Governance }\end{array}$ & 1.312 & 3 \\
\hline DS1 & $\begin{array}{l}\text { Define and } \\
\text { manage } \\
\text { service levels }\end{array}$ & 2.300 & 3 \\
\hline DS2 & $\begin{array}{l}\text { Manage } \\
\text { third-party } \\
\text { Services }\end{array}$ & 2.025 & 3 \\
\hline DS3 & $\begin{array}{l}\text { Manage } \\
\text { performance } \\
\text { and capacity }\end{array}$ & 2.500 & 3 \\
\hline DS4 & $\begin{array}{l}\text { Ensure } \\
\text { continuous } \\
\text { service }\end{array}$ & 1.500 & 3 \\
\hline DS5 & $\begin{array}{l}\text { Ensure } \\
\text { systems } \\
\text { security }\end{array}$ & 1,62 & 3 \\
\hline DS6 & $\begin{array}{l}\text { Identify and } \\
\text { allocate cost }\end{array}$ & 1.885 & 3 \\
\hline
\end{tabular}




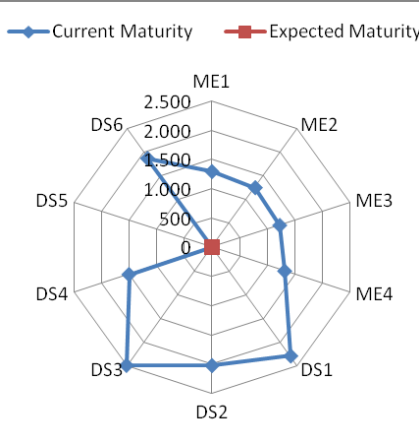

Gambar 2.3: Gap tingkat Motivasi dan Kompetensi (maturity level) domain Deliver and Support dan domain Monitor and Evaluate

\subsection{Implikasi Penelitian}

Dari hasil perhitungan maturity level dapat dilihat bahwa maturity level penggunaan edmodo masih berkisar pada level 1 (initial/ad-hoc) dan 2 (repeatable but intuitive). Sedangkan maturity level yang diharapkan adalah 3 (define process). Untuk menutup gap tersebut maka harus dilakukan perbaikan di keseluruhan proses elearning pada domain DS dan ME.

Untuk perbaikan ini berikut diberikan rekomendasi hal-hal yang harus dilakukan agar persyaratan pemenuhan di tiap proses terpenuhi sehingga tingkat penggunaan edmodo yang diinginkan (expected maturity level) dapat dicapai.

Berikut ini adalah kegiatan yang harus dilakukan agar penggunaan edmodo yang diinginkan (expected maturity level) tercapai, disertai dengan indikator pengukurannya. Beberapa hal yang disampaikan yang harus dilakukan merujuk pada detail control objective masing-masing proses.

1. DS1 Define and manage service levels (menetapkan dan mengelola tingkat layanan). Fokus utama proses DS1 adalah mengidentifikasi persyaratan-persyaratan edmodo, persetujuan terhadap mutu edmodo, dan memonitor pencapaian setiap mutu edmodo.

2. DS2 Manage third-party services (mengelola layanan dari pihak ketiga). Fokus utama proses DS2 adalah membangun relationship dan tanggung jawab bilateral dengan pihak ketiga penyedia yang berkualitas dan pemantauan penyampaian layanan untuk verifikasi dan memastikan ketaatan persetujuan yang telah ditetapkan.

3. DS3 Manage performance and capacity (mengatur kinerja dan kapasitas). Fokus utama proses DS3 adalah memenuhi persyaratan waktu respon dari persetujuan mutu e-learning, meminimalkan down time, dan membuat peningkatan kapasitas dan kinerja edmodo yang berkesinambungan, melalui pengawasan dan pengukuran.

4. DS4 Ensure continuous service (menjamin keberlangsungan layanan). Fokus utama proses DS4 adalah menyediakan e-learning yang berkesinambungan membutuhkan pengembangan, pemeliharaan, dan pengujian perencanaan e-learning yang berkesinambungan pula. Proses layanan yang secara efektif berkesinambungan meminimalkan kemungkinan dan dampak dari interupsi layanan utama e-learning pada proses-proses dan fungsi-fungsi utama perkuliahan.

5. DS5 Ensure systems security (menjamin keamanan sistem). Fokus utama proses DS5 adalah mendefinisikan kebijakan, prosedur, dan standar keamanan edmodo, serta memonitor, mendeteksi, melaporkan, dan menyelesaikan kerentanan keamanan dan insiden.

6. DS6 Identify and allocate costs (mengidentifikasi dan mengalokasikan biaya). Fokus utama proses DS6 adalah gambaran biaya penggunaan elearning yang lengkap dan akurat, sistem alokasi biaya yang fair yang disetujui oleh akademik, dan sistem pelaporan alokasi biaya dan pemakaian edmodo yang tepat waktu.

7. Alokasi biaya TI belum memiliki standar baku atau asumsi biaya belum sempurna. Proses alokasi biaya masih merupakan perulangan

8. ME1 Monitor and evaluate IT performance (mengawasi dan mengevaluasi kinerja TI). Fokus utama proses ME1 adalah mengawasi dan melaporkan matrik proses e-learning edmodo serta mengidentifikasi dan mengimplementasi kemampuan melakukan perbaikan.

9. ME2 Monitor and evaluate internal control (mengawasi dan mengevaluasi kontrol internal). Fokus utama proses ME2 adalah memonitor kontrol proses yang ada didalam edmodo yang berhubungan dengan aktivitas dan identifikasi kemajuan e-learning.

10. ME3 Ensure regulatory compliance (menjamin kepatuhan hukum). Fokus utama: mengidentifikasi semua hukum dan peraturan yang diterapkan dan berhubungan 
dengan e-learning dan jaminan proses edmodo akan mengurangi resiko karena ketidak patuhan.

11. ME4 Provide IT Governance (menyediakan tata kelola TI). Fokus utama: menyiapkan laporan kepada pimpinan/akademik mengenai strategi e-learning edmodo, kinerja dan resiko serta memberikan respon persyaratan edmodo yang sesuai dengan arahan pimpinan/akademik

\section{PENUTUP}

Beberapa kesimpulan yang dapat diambil dari penelitian yang telah dilakukan adalah sebagai berikut.

1. Proses perkuliahan menggunakan edmodo untuk mendukung sistem perkuliahan elearning sudah dilakukan tetapi belum optimal, mengingat sebagian besar prosedur belum dibakukan. Dokumentasi sudah dilakukan tetapi tidak dilakukan update secara rutin, apabila ada perubahan prosedur tidak serta merta didokumentasikan.

2. Hasil perhitungan tingkat motivasi dan kompetensi penggunaan edmodo (maturity level) yang ada pada setiap proses e-learning yang terdapat dalam domain Delivery and Support (DS) dan Monitor and Evaluate (ME) pada umumnya berbeda-beda, tetapi sebagian besar ternyata masih berada pada level 1 (initial/ad-hoc), walaupun ada satu proses e-learning yang sudah berada di level 2 (repeatable but intuitive). Untuk dapat mencapai tingkat motivasi dan kompetensi penggunaan edmodo yang diinginkan (expected maturity level) di level 3 (defined process) maka semua prosedur yang disyaratkan di tiap proses harus dipenuhi. Mengacu pada standarisasi COBIT untuk dapat mencapai level 3 (defined process) maka setiap proses yang e-learning harus memiliki prosedur baku dan tertulis yang disosialisasikan ke semua pihak yang terlibat dalam sistem informasi akademik, yaitu kepada pengelola sistem dan pengguna langsung sistem. Prosedur tersebut harus didokumentasikan dan di-update secara berkala.

3. Dari hasil analisa gap antara tingkat motivasi dan kompetensi penggunaan edmodo saat ini dengan tingkat motivasi dan kompetensi yang ingin dicapai, maka dapat dikatakan bahwa semua proses e-learning edmodo harus diperbaiki. Pada domain DS prioritas perbaikan dilakukan pada proses
DS4 (ensure continous service), diikuti oleh DS5 (ensure system security), dan DS6 (identify and allocate cost). Sedangkan untuk domain ME prioritas perbaikan dilakukan di proses ME2 (monitor and evaluate internal kontrol), dan diikuti dengan proses-proses yang lain, karena secara keseluruhan proses TI pada domain ME perlu perbaikan. Tindakan perbaikan mengacu pada dokumen high level control objective yang disediakan oleh COBIT.

\section{DAFTAR PUSTAKA}

[1] Budi Murtiyasa. 2012. Pemanfaatan Teknologi Informatika dan Komunikasi untuk meningkatkan Kualitas Pembelajaran Matematika. Surakarta : FKIP Univ. Muhammadiyah Surakarta.

[2] IT Governance Institute. (2007). COBIT 4.1 Framework, Control Objectives, Management Guidelines, Maturity Models. Rolling Meadows, IL 60008, USA: IT Governance Institute

[3] L.R Gay, Educational Research : Comptencies For Analysis and Application (New York:Macmillan Publishing Company)

[4] Sasongko, Nanang, 2009, Pengukuran Kinerja Teknologi Informasi Menggunakan Framework Cobit Versi. 4.1, Ping Test Dan Caat Pada Pt.Bank X Tbk. Di Bandung.

[5] Thomson, R., Higgin, C. A., dan Howell, J. M., Personal Computing: Toward a Conceptual Model of Utilization, MIS Quartery, 1991.

[6] Zaini, Hisyam. Dkk. 2002. Strategi Pembelajaran Aktif. Yogyakarta : CTSD IAIN Sunan Kali Jaga 